\title{
Resolvins and protectins: novel lipid mediators in anti-inflammation and resolution
}

\author{
Charles N. Serhan ${ }^{1,2}$
}

\begin{abstract}
'Center for Experimental Therapeutics and Reperfusion Injury, Department of Anesthesiology, Perioperative and Pain Medicine, Brigham and Women's Hospital, Boston, Massachusetts, USA; ${ }^{2}$ Department of Oral Medicine, Infection and Immunity, Harvard School of Dental Medicine and Harvard Medical School, Boston, Massachusetts, USA
\end{abstract}

\begin{abstract}
A well-integrated inflammatory response and its natural resolution are essential to homeostasis. Hence, it is important to achieve a complete understanding of the molecular events that govern termination of acute inflammation. Recent studies uncovered endogenous pathways in inflammatory exudates taken from the resolution phase that actively generate new families of locally acting mediators from the essential fatty acids eicosapentaenoic acid and docosahexaenoic acid. These new chemical families were coined resolvins and protectins because in animals specific members of these families control the duration and magnitude of inflammation. Hence, mapping of these resolution circuits, mediators and their target signaling pathways of these potent agonists of resolution has provided new avenues for appreciating the molecular basis of many inflammatory diseases. This overview covers recent advances on the biosynthesis and actions of these novel anti-inflammatory lipid mediators, with a focus on the stereochemical basis of the potent actions of resolvin E1 and protectin D1. These previously unappreciated families of lipid-derived mediators were originally isolated from experimental murine models of acute inflammation captured during natural self-limited resolution. Since they have proven anti-inflammatory, proresolving, and protective properties in experimental models of disease, it follows that potential defective resolution mechanism(s) may underlie the current appreciation of inflammatory disease phenotype(s).
\end{abstract}

Keywords: anti-inflammatory; aspirin; human leukocytes; lipid mediators

Abbreviations: AA: arachidonic acid; COX: cyclooxygenase; DHA: docosahexaenoic acid; EPA: eicosapentaenoic acid; GPCR: G-protein-coupled receptors; HDHA: hydroxydocosahexaenoic acid; HEPE: hydroxyeicosapentaenoic acid; LC: liquid chromatography; LO: lipoxygenase; MS-MS: tandem mass spectrometry; NPD1: neuroprotectin D1; PDI: protectin D1; PMN: polymorphonuclear neutrophil; PUFA: polyunsaturated fatty acid; RvE1: resolvin E1; UV: ultraviolet.

\section{Introduction}

$\mathrm{T}$ he essential roles of omega-3 (n-3) polyunsaturated fatty acids (PUFAs) in health were evident as early as 1929 (1). Although studied until the present, the mechanism of action of eicosapentaenoic acid (EPA) and docosahexaenoic acid (DHA), the major n-3 PUFAs in human systems, remains a topic of debate (2-5). Inflammation has emerged in recent years as playing a key role in many prevalent diseases not previously known to involve inflammation. These include Alzheimer's disease and cardiovascular disease (6), as well as cancer (7), which now join the well-known inflammatory disorders such as arthritis and periodontal disease $(8-10)$. The molecular mechan- ism(s) underlying the many reports of the beneficial actions of n-3 PUFAs remains an important challenge for molecular medicine. To this end, novel oxygenated products were identified, generated by enzymic pathways initiated from the precursors EPA and DHA. These new compounds are biosynthesized and possess potent actions in the resolution of inflammatory exudates (11-13) and are also neuroprotective $(14,15)$. The term resolvins (resolution phase interaction products) was first introduced to signify that the new structures were endogenous mediators possessing very potent antiinflammatory and immunoregulatory actions (12), which include reducing neutrophil traffic, cytokine and reactive oxygen species regulation, as well as 
Table I. Actions of $\mathrm{E}$ and $\mathrm{D}$ series resolvins

\begin{tabular}{lll}
\hline Mediator & Action & References \\
\hline Resolvin EI & $\begin{array}{l}\text { Reduces PMN infiltration, murine skin air } \\
\text { pouch inflammation and peritonitis } \\
\text { Gastrointestinal protection in TNBS colitis } \\
\text { Protects in periodontitis; stops inflammation } \\
\text { and bone loss in rabbits }\end{array}$ & Serhan et al., 2000, 2002 (II, I2), Arita et al., 2005 (I9) Bannenberg et al., 2005 (20) \\
& $\begin{array}{l}\text { Reduces PMN infiltration and murine skin air } \\
\text { pouch inflammation } \\
\text { Reduces peritonitis and microglial cell cytokine } \\
\text { expression }\end{array}$ & Hasturk et al., 2005 (22) \\
& $\begin{array}{l}\text { Protects in renal ischemic injury and limits PMN } \\
\text { infiltration }\end{array}$ & Hong et al., 2003 (I3) \\
\hline
\end{tabular}

PMN: polymorphonuclear neutrophil; TNBS: 2,4,6-trinitrobenzene sulfonic acid (see text for further details).

lowering the magnitude of the inflammatory response in vivo $(11,12)$. The terms protectin and neuroprotectin, when generated in the neural tissues (16), were introduced given the anti-inflammatory (13) as well as the protective actions of the 10,17docosatriene in neural systems (15), stroke (14) and animal models of Alzheimer's disease (10).

In contrast to the earlier oxygenated products characterized as being formed from n-3 PUFAs that are similar in structure to known arachidonic acid (AA)-derived eicosanoids, but less potent or devoid of bioactions $(17,18)$, specific members of the resolvin and protectin families evoke potent biological actions demonstrable in the nanomolar and

Table 2. Protectins: formation and actions of protectin DI/neuroprotectin DI

\begin{tabular}{ll}
\hline Key actions and organ system & Reference \\
\hline Reduces PMN infiltration & Hong et al., 2003 (I3) \\
$\begin{array}{l}\text { Limits stroke damage and PMN entry into } \\
\text { the brain }\end{array}$ & Marcheselli et al., 2003 (I4) \\
$\begin{array}{l}\text { Protects from retinal injury } \\
\text { Regulates } \mathrm{T}_{\mathrm{H}} 2 \text { cells and apoptosis }\end{array}$ & Mukherjee et al., 2004 (I5) \\
$\begin{array}{l}\text { Limits T-cell recruitment in peritonitis } \\
\text { Shortens resolution interval in murine } \\
\text { peritonitis; regulates cytokines and } \\
\text { chemokines }\end{array}$ & Ariel et al., 2005 (24) \\
$\begin{array}{l}\text { Reduces PMN infiltration; reduces peritonitis } \\
\text { Diminished production in human Alzheimer's } \\
\text { disease; promotes neural cell survival }\end{array}$ & Serhan et al., 2006 (I6) \\
$\begin{array}{l}\text { Promotes corneal epithelial cell wound } \\
\text { healing and repair }\end{array}$ & Gronert et al., 2005 (20) \\
Liver protective & \\
\hline
\end{tabular}

PMN: polymorphonuclear neutrophil. picomolar ranges in vitro and in vivo (10-15) (Tables 1 and 2).

\section{Chemical mediators in inflammation and resolution}

Early studies by Bergström, Samuelsson and colleagues established that $\mathrm{AA}$ is transformed into many potent bioactive compounds such as prostaglandins, leukotrienes and lipoxins $(27,28)$. The departure of fatty acids from simply playing structural roles in cell membranes or as energy stores came with the recognition that AA is transformed by both cyclooxygenase and lipoxygenase mechanisms to potent eicosanoid mediators, which led to a Nobel prize in 1982 (27, 29, 30). Most of the classic prostaglandins and leukotriene mediators are proinflammatory and also play specific roles in the reproductive system. It was assumed that these same mediators were formed and served in the initiation and termination of acute inflammation (Fig. 1) as well as in the turn from acute to chronic inflammation (33). However, in sharp contrast, it has become clear that counter-regulatory substances, such as lipoxins, are generated during the resolution of acute inflammation to serve in healthy termination of an acute response $(34,35)$. It is important to note that these chemical mediators serve as agonists for endogenous anti-inflammatory and proresolving mechanisms. Hence, the first evidence that the resolution of inflammation, which was once thought to be a passive process (36), is actually an active biochemical process that turns on specific proresolution biochemical signaling circuits came with the identification of specialized chemical 


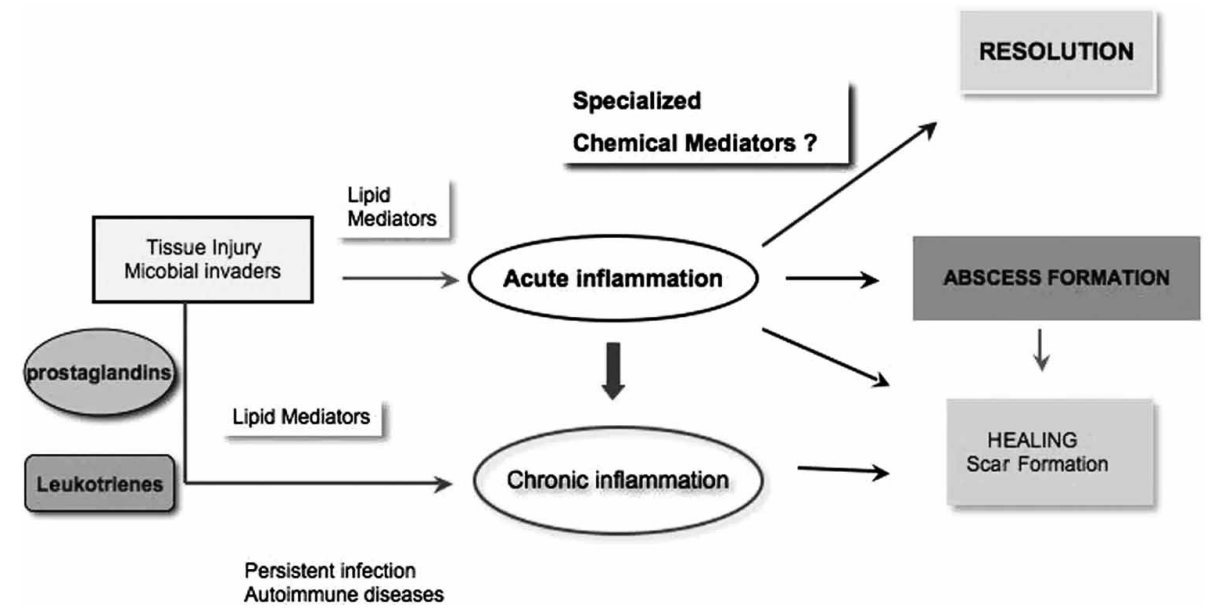

Fig. 1. Progression and outcomes of acute inflammation: roles of chemical mediators. A temporal illustration of the fate of acute inflammation (31). The chemical mediators involved in the initiation of acute inflammation such as prostaglandins and leukotrienes are assumed to be the same as those involved in the termination or resolution of inflammation. Specialized chemical mediators appear to be programmed in a tissuelevel response to participate actively in leukocyte responses required for resolution. (See text and ref. 32.)

mediators biosynthesized during the resolution phase such as the resolvins that actively promote resolution $(34,37,38)$ and the return to homeostasis (37) (see below).

In general, this is a departure from the wellappreciated proinflammatory roles of lipid mediators (28). The recognition that resolution is an active process and that activation of the lipoxin biosynthetic circuit and lipoxins themselves, as well as aspirin-triggered lipoxins and their stable analogs, are potent agonists of anti-inflammation in vivo and in many disease models (37), has now focused our attention on understanding the biochemical events activated during healthy resolution of acute inflammatory responses and ischemia reperfusion injury.

\section{A compelling connection for $n-3$ polyunsaturated fatty acids}

The GISSI results showed, from a randomized study of over 11000 patients with cardiovascular disease, a reduction in sudden death of around $45 \%$ in those taking almost $1 \mathrm{~g}$ of $\mathrm{n}-3$ per day $(39,40)$. In view of these findings, the present author questioned the mechanism of this n-3 action in humans with vascular disease. Inspection of the GISSI protocol indicated that patients in each arm of the study groups were taking aspirin daily. However, the contributions of ongoing aspirin therapy to the beneficial outcomes with the group taking n-3 were not taken into account (39). In addition, an abundant literature with n-3 PUFAs given at doses of milligrams to grams per day pointed to beneficial actions in many diseases including inflammatory diseases as well as cancer $(2,41)$. Each of the three major human lipoxygenases (5-LO, 12-LO, 15-LO) can convert n-3 PUFAs to various monohydroxycontaining products. The biological importance of these products, if any, was not known $(18,42,43)$. DHA can also be non-enzymically oxygenated to isoprostane-like compounds termed neuroprostanes that reflect oxidative stress in the brain (44) or can undergo autooxidization to products that are monohydroxy racemates (45). Thus, despite the many decades of research with n-3 PUFAs, the cellular and molecular basis underlying their regulatory and immunoprotective actions remained for the most part unknown.

\section{Aspirin and specialized chemical mediators in resolution}

Aspirin is in many over-the-counter remedies, making it difficult to control for in many human studies. Moreover, although it is clear that aspirin inhibits prostaglandin formation and hence a key mechanism in anti-inflammatory therapy (29), and that aspirin has well-appreciated clinical uses and an ability to limit leukocyte traffic into sites of inflammation, the key player in propagating inflammation remained unknown. To address this, studies by this group first used murine dorsal skin pouches $(11,12)$ known to resolve spontaneously in rats $(38,46)$. This system was adapted for study in mice, in order to assess genetic contributions to resolution and develop mediator informatics and lipidomics using liquid chromatography (LC)-ul- 
traviolet (UV)-tandem mass spectrometry (MSMS)-based analyses of inflammatory exudates. The author's group also constructed lipid mediator libraries with physical properties, such as MS and MS/MS spectra, elution times and UV spectra for matching studies, as well as to assess whether known and/or potential novel lipid mediators were present within the exudates $(47,48)$. These databases and informatics were geared to evaluate whether novel lipid mediators are indeed generated during the resolution phase of inflammation $(11,12)$.

In this experimental model of a contained inflammation (Fig. 1), after $4 \mathrm{~h}$, polymorphonuclear neutrophil (PMN) numbers drop within the exudates $(11,12)$, namely, the cellular definition of resolution (31). Exudates were taken in these intervals, focusing on the period of "spontaneous resolution" (46); namely, when neutrophils are lost from the exudate and the tissue sites appear to resolve (Fig. 2, left). In this phase of the response in vivo, lipid mediator profiles were recorded using tandem LC-UV-MS-MS to identify lipid mediators present within the exudates. When novel bioactive mediators were encountered, their structures were elucidated. This was accomplished by carrying out retrograde analysis for both biogenic (i.e. using recombinant enzymes) and total organic synthesis. This approach also permitted assessment of structure-activity relationships as well as the scale-up required to confirm bioactions characterized for the novel compounds identified $(19,47)$.

\section{Resolvins: I8R E series and I7R D series}

Resolving exudates contained $18 R$-hydroeicosapentaenoic acid (18R-HEPE) (Fig. 2, right) as well as several other related bioactive compounds (11). These novel compounds were produced from EPA. The first bioactive compound was isolated from exudates and found to reduce inflammation in vivo as well as block human neutrophil transendothelial migration. Structural elucidation was carried out using both gas chromatography-MS and LC-MSMS analysis of bioactive fractions obtained following extraction and reverse-phase high-performance liquid chromatography. The basic structure of the potent bioactive product generated in exudates from EPA proved to be 5,12,18R-trihydroxyeicosapentaenoic acid (11). Isolated cyclooxygenase-2 (COX-2) treated with aspirin generates 18R-HEPE as well as 15R-HEPE, which are blocked by selective COX-2 inhibitors. This 15R-HEPE is a precursor to the 15epi-lipoxin A5 series from EPA that shares the
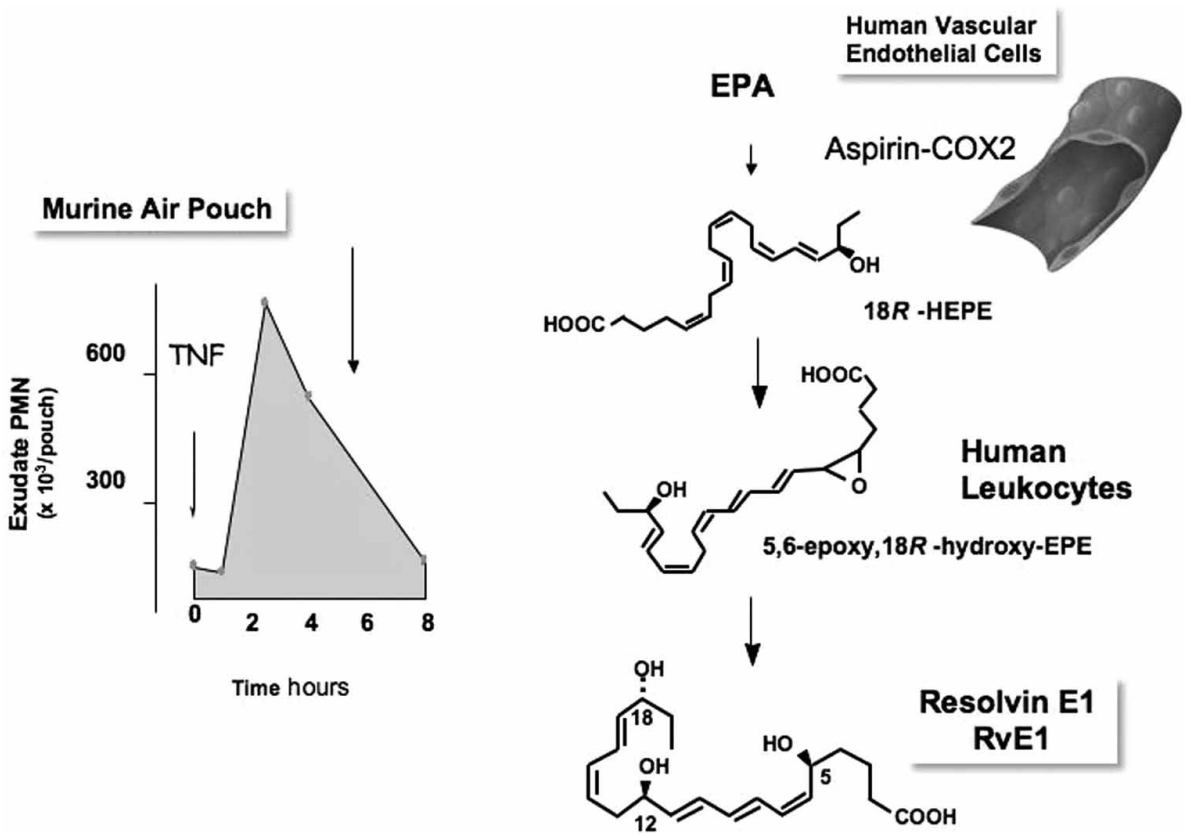

Fig. 2. Biosynthesis of resolvin E1. Left: murine air pouch model of contained inflammation and self-limited resolution. The arrow denotes decreasing neutrophil numbers at the dorsal inflammatory site and the points when resolving pathways and products were obtained for mass spectral and bioassay analysis. Right: human endothelial cells expressing cyclooxygenase-2 (COX-2) treated with aspirin transform eicosapentaenoic acid (EPA) by abstracting hydrogen at carbon 16 to give $R$ insertion of molecular oxygen to yield $18 R$-hydro(peroxy) eicosapentaenoic acid [18R-H(p)EPE]. They are further converted via sequential actions of leukocyte 5-lipoxygenase and lead to the formation of resolvin E1. TNF: tumor necrosis factor; PMN: polymorphonuclear neutrophil. (See text and refs 11, 12 and 19.) 
potent anti-inflammatory actions of lipoxins of the 4 series. The 5 series EPA-derived lipoxins were identified earlier as major endogenous mediators in fish (49). Surprisingly, acetaminophen and indomethacin, at clinically used doses, permitted oxygenation of EPA to both 18R-HEPE and 15R-HEPE with isolated COX-2, although the levels of both were significantly reduced. These results indicate that the oxygenation of n-3 PUFAs to generate novel bioactive mediators can also involve certain widely used anti-inflammatory drugs, but not selective COX-2 inhibitors (11).

Next, the most likely human pathway that was a source of these bioactive mediators within the inflammatory exudates was reconstructed in vitro and found to involve cell-cell interactions that could potentially contribute to the generation of these bioactive mediators in vivo within the exudates. As determined with isolated human cells, vascular endothelial cells treated with aspirin convert EPA to $18 R$-HEPE, which is released and then rapidly converted by activated human PMN to a 5(6) epoxide-containing intermediate that is converted to the bioactive 5,12,18R-trihydroxy-EPE. This bioactive compound was termed resolvin E1 (RvE1), because it proved to be a potent regulator of PMN transmigration and inflammation in vivo. RvE1 possesses an interesting and novel distinct structure consisting of a conjugated triene plus conjugated diene chromophore present within the same molecule. Both biogenic (11) and total organic synthesis was achieved and its complete stereochemical assignment was recently established (19). RvE1 proved to be $5 S, 12 R, 18 R$-trihydroxy$6 Z, 8 E, 10 E, 14 Z, 16 E$-eicosapentaenoic acid. This compound displayed potent stereoselective actions in vivo and with isolated cells (Table 1 and references therein). Therefore, evidence was sought for the ligand-specific receptors for RvE1 ligand that were identified using a signal screening approach and a synthetic radiolabeled RvE1. Other geometric isomers related to RvE1 were prepared and proved to be less potent than RvE1 and did not share the physical properties of endogenous RvE1 (see ref. 19, along with the supplemental material).

The resolving exudates from mice given aspirin plus DHA also contained novel $17 R$-hydroxydocosahexaenoic acid (17R-HDHA) and two separate novel families of bioactive compounds (Fig. 3). Here, too, the biosynthetic pathways were reconstructed in vitro to establish a potential origin for these novel compounds found in vivo. Along these lines, hypoxic human microvascular endothelial cells treated with aspirin released $17 R$-HDHA and DHA, which are converted by isolated human recombinant COX-2 to 13-hydroxy-DHA. With aspirin, this switches to $17 R$-oxygenation with molecular oxygen to give an epimeric aspirintriggered form at sites of exudate formation (Fig. 4) and also in the brain $(12,13)$ of both families, resolvins and protectins, which carry a $17 R$ alcohol group configuration instead of $17 S$ when biosynthesized via lipoxygenase mechanisms (see Fig. 3 and below).

\section{Resolvins of the I7S D series and protectins}

Using this lipid mediator informatics approach, it was found that neither aspirin nor exogenous DHA was required to produce these compounds in vivo. The endogenous DHA was converted in vivo to a $17 S$ alcohol-containing series of resolvins, depicted in Figs. 3 and 4, as well as docosatriene-containing structures via lipoxygenase-initiated mechanisms $(13,14)$. The complete stereochemistry of protectin D1 (PD1), which carries a 10,17-dihydroxydocosatriene structure $(12,13)$, was recently established. Total organic synthesis of related isomers and matching studies with biologically derived materials showed that endogenous PD1, called neuroprotectin D1 (NPD1) when produced by neural tissues, was recently established in isolated human cells in vitro and murine cells in vivo as $10 R, 17 S$-dihydroxydocosa-4Z,7Z,11E,13E,15Z,19Z-hexaenoic acid (16). The geometry of the double bonds in PD1 and their positions during biosynthesis from the key intermediates in its biosynthesis in situ, namely via an epoxide intermediate at the 16(17) position, indicated that PD1 biosynthesis requires enzymic steps to generate the potent bioactive molecule from DHA (Fig. 5).

PD1 proved to be log orders of magnitude more potent than its precursor DHA, indicating that it is a chemical autacoid (13). The formation of potent bioactive mediators from DHA was proposed as early as 1984 by Bazan (50). In collaboration with Bazan and colleagues $(10,14,15)$, the present author documented the formation of NPD1 and identified actions that suggest that it is an important mediator in neural systems (Table 2). Identification of the resolvins and protectins generated from DHA now opens exploration into the essential roles of these pathways and mediators in human systems. 


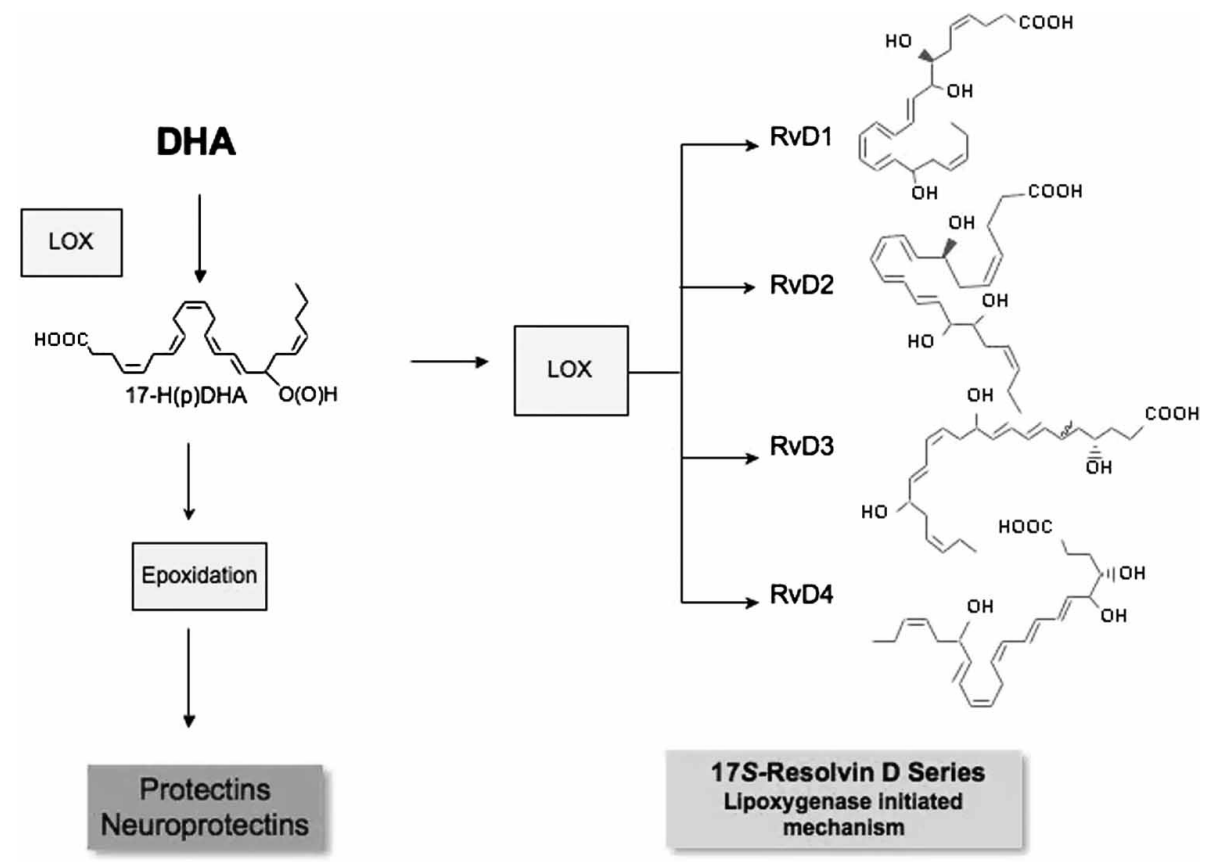

Fig. 3. Overview of resolvins and protectins: biosynthesis from docosahexaenoic acid (DHA). DHA is the precursor to and is enzymically transformed to two families of chemically distinct mediators that demonstrate potent actions in vitro and in vivo. These include resolvins of the $\mathrm{D}$ series and the protectins. The distinguishing features of these two families of chemical structures are as follows. The protectins carry three of their six double bonds in a conjugated triene system and thus display a distinct conjugated triene chromophore. The resolvins of the D series are subject to two sequential lipoxygenation steps and carry four of their six double bonds in a conjugated tetraene structure, and exhibit a characteristic tetraene chromophore. Resolvins and protectins each carry a 17-position alcohol group that is inserted via lipoxygenase in the $S$ configuration. Both families are also generated in an aspirin-dependent fashion that inserts oxygen at the 17-position in the $R$ configuration, demonstrated with recombinant acetylated cyclooxygenase-2. Hence, the aspirin-triggered epimeric forms of the protectins and resolvins are denoted AT-resolvins and AT-protectins. When protectin D1, which is a demonstrated anti-inflammatory and has potent actions in neural systems, is generated within neural systems, it is prefixed with neuro to give its organ location, since the same biochemical pathway and utilization of DHA exist in both immune and neurological systems. LOX: lipoxygenase. (See text and Fig. 4 for details.)

The structures and pathways of the D-series resolvins are shown in Figs. 3-5. Their basic structures and actions have been determined (see below) (Table 2). The complete stereochemical assignments of resolvins D1 to D4 are in progress and will be reported elsewhere.

\section{Resolvins and protectins in disease models: formation and actions}

Resolvins of the E series comprise several molecules. Among them, RvE1 was the first to be isolated and studied in depth. At nanomolar levels, RvE1 dramatically reduced neutrophil transendothelial migration, dermal inflammation $(12,19,51)$, peritonitis, dendritic cell migration and interleukin-12 production (Table 1). Administration of synthetic RvE1 blocks PMN infiltration in periodontal disease in a rabbit model (22) and protects against the development of 2,4,6-trinitrobenzene sulfonic acid (TNBS)-induced colitis (21). Therefore, it was of interest to determine the receptors involved in its bioactions. To this end, screening a library of G- protein-coupled receptors (GPCRs) (19), the orphan receptor ChemR23 was found to bind specifically to ${ }^{3} \mathrm{H}$-labeled $\mathrm{RvE}$, thereby attenuating nuclear factor- $\kappa \mathrm{B}$ signaling. Using a structurefunction approach, a second high-affinity GPCR was identified, which signals in response to RvE1 (19). The main second messenger for RvE1 agonist actions via these GPCRs appears to be activation of intracellular phosphorylation pathways, rather than mobilization of intracellular calcium or cyclic adenosine monophosphate (cAMP) as with most proinflammatory mediators $(19,21)$. Thus, in several animal models of inflammatory diseases, RvE1 displays potent counter-regulatory actions that protect against leukocyte-mediated tissue injury and excessive proinflammatory gene expression $(19,21,22)$.

Resolvins of the $\mathrm{D}$ series block tumor necrosis factor- $\alpha$-induced interleukin- $1 \beta$ transcripts in microglial cells and also act as potent regulators limiting PMN infiltration into inflamed brain, skin and peritonitis (12-14). Direct comparisons 


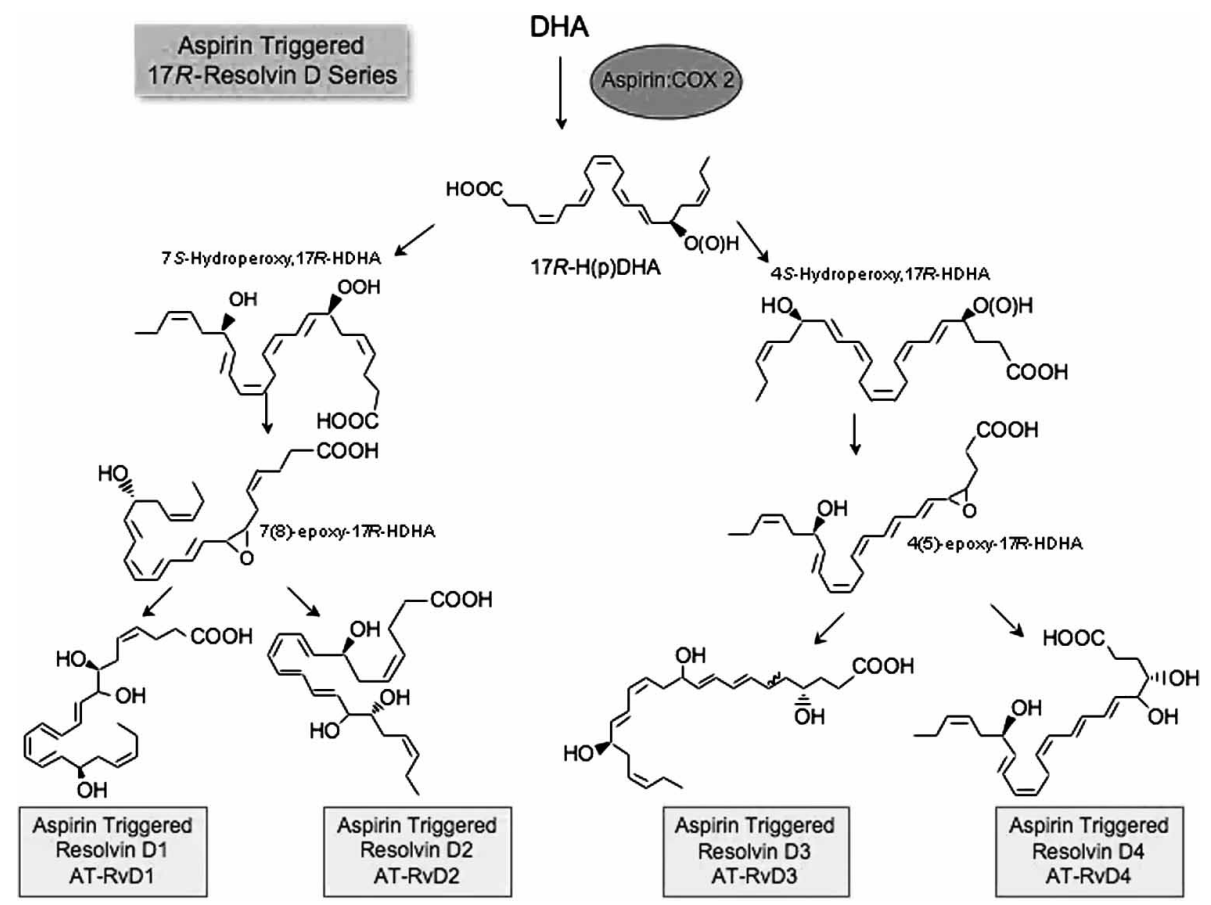

Fig. 4. Conversion of docosahexaenoic acid (DHA) to aspirin-triggered D series resolvins. The $17 R$ series resolvins are produced from DHA in the presence of aspirin. Human endothelial cells expressing cyclooxygenase-2 (COX-2) treated with aspirin transform DHA to $17 R$-HDHA. Human polymorphonuclear neutrophils can then convert $17 R$-HDHA to two separate intermediates via 5-lipoxygenation (11) that are each rapidly transformed into two epoxide intermediates, 7(8)-epoxide (left) and another 4(5)-epoxide-containing intermediate (right). These two novel epoxide intermediates open via enzymic hydration to give the stereochemistry required for the bioactive products denoted $17 S$ series RvD1 to RvD4. RvD1 to RvD4 appear to be functionally redundant positional isomers generated via the actions of specific enzymes. Their complete stereochemical assignments are in progress and are depicted as tentative geometries of their respective double bonds. Aspirin triggers the same compound, but chirality at carbon 17 is in the $R$ configuration from the involvement of COX-2 when acetylated by aspirin.

between the resolvin $\mathrm{E}$ versus both of the $\mathrm{D}$ series $(17 S$ and $17 R$ epimer aspirin-triggered series) at equal doses demonstrated that the new $17 \mathrm{~S}$ series generated by lipoxygenase-initiated mechanisms and those of the $17 R$ series RvDs that are triggered by aspirin treatment administered intravenously at $100 \mathrm{ng}\left[\sim 3 \mu \mathrm{g} \mathrm{kg}^{-1}\right]$ in mice display essentially similar actions, reducing PMN infiltration by approximately $50 \%$ in peritonitis, compared with around $75-80 \%$ inhibition by RvE1. For the purpose of direct comparison, indomethacin, a widely used anti-inflammatory, at the same doses produced a reduction in leukocyte infiltration of about $25 \%(12,13)$. Thus, both the RvDs $(17 S$ series) and aspirin-triggered RvDs (17R series) are potent regulators of PMN infiltration in vivo, and the $S$ to $R$ switch with aspirin treatment in the biosynthesis of the 17 position alcohol in the omega side-chain does not diminish their activity. This implicates that the aspirin-triggered $17 R$ epimers of protectins and resolvins may each serve as the body's own anti-inflammatory mediators in response to aspirin.

\section{Protectins}

Protectins possess a conjugated triene-containing structure as the key feature of this new family of compounds derived from DHA. The 10,17S-docosatriene formed in the NPD1 pathway (Figs. 3 and 5) proved to be a potent regulator of PMN influx in exudates at the site where it is formed from endogenous precursors $(12,13)$, and limits stroke brain injury (14) and retinal cells (15). Other dihydroxy-docosanoids (both positional and geometric isomers) were substantially less bioactive $(13,15,16)$. PD1, also referred to as NPD1 when generated in the nervous system, possesses potent actions in vitro and in vivo (Table 2). The complete stereochemistry of PD1, namely chirality of the alcohol groups and geometry of the conjugated triene, was recently established in human cells as $10 R, 17 S$-dihydroxy-docosa- $4 Z, 7 Z, 11 E, 13 E$, 15Z, 19Z-hexaenoic acid (16). 


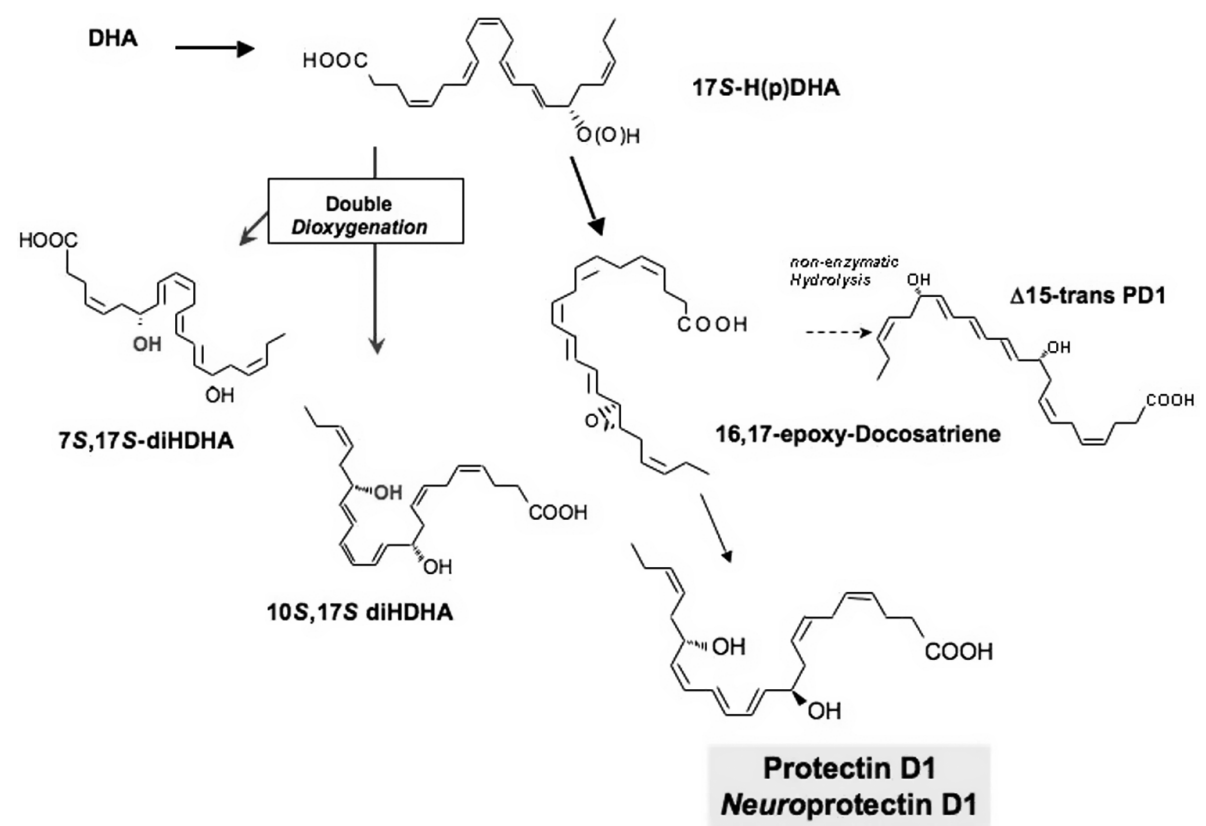

Fig. 5. Protectin/neuroprotectin D1 biosynthetic pathway. The initial enzymic product $17 S$-hydro(peroxy)docosahexaenoic acid [17S$\mathrm{H}(\mathrm{p}) \mathrm{DHA}$ ] is converted to a 16(17)-epoxide containing intermediate by leukocyte and microglial cells and enzymically converted to the 10,17-dihydroxytriene-containing bioactive product (13) denoted earlier as 10,17S-docosatriene (14) and recently coined neuroprotectin D1 based on its potent actions in vivo $(14,15)$. (See text and Table 2 for further details.) The complete stereochemistries of the bioactive mediators and related isomers were established and are shown as indicated (16). DHA: docosahexaenoic acid.

Synthetic PD1 at $10 \mathrm{nM}$ attenuates human neutrophil transmigration by about $50 \%$ in vitro, whereas its $\Delta 15$-trans-isomer is essentially inactive. PD1 is also a potent regulator of PMN in vivo by reducing PMN infiltration $(\sim 40 \%$ at $1 \mathrm{ng}$ per mouse) in murine peritonitis. PD1 also reduced PMN infiltration when administered after the initiation of inflammation in vivo, as well as acting in an additive fashion with RvE1 to stop PMN infiltration. These results indicate that PD1 is a potent, stereoselective anti-inflammatory molecule (12, 13, 16). Moreover, these results and those obtained together with Bazan and colleagues in neural tissues demonstrate that PD1 displays potent immunoregulatory $(12,13,16)$ and neuroprotective actions $(10,14,15)$ as well as promoting wound healing capacity (25). PD1/NPD1 limits stroke brain injury (14) and retinal pigmented cellular damage and promotes brain cell survival, suppressing A $\beta 42$-induced neurotoxicity (15) (Table 2). The protection upon oxidative stress with NPD1 involves up-regulation of the antiapoptotic Bcl-2 and $\mathrm{Bcl}-\mathrm{x}(\mathrm{L})$ in response to NPD1 treatment, whereas the proapoptotic Bax and Bad are down-regulated, resulting in reduced caspase-3 cleavage (10). Taken together, these are the first results indicating that novel lipid mediators are generated and present in resolving exudates derived from n-3 fatty acids. This work also established that these novel compounds derived from EPA and DHA carry anti-inflammatory properties and that they are log orders more potent than their precursors in vivo.

\section{Conclusion}

The new families of EPA- and DHA-derived chemical mediators reviewed here, namely the resolvins and protectins, now open new avenues to design resolution-targeted therapies to control unwanted side-effects of aberrant inflammation. These n-3-derived lipid mediators act as agonists at different steps in the progression of inflammation that appear to be temporal and spatially distinct within the resolution phase (32). It follows that endogenous lipid mediators play key roles in controlling and programming resolution of inflammation as an active bioprocess (11). Identification of anti-inflammatory bioactions of the lipoxins and of aspirin-triggered lipoxin dispel the dogma that all AA-derived mediators are solely proinflammatory (35). These findings lead to a deeper appreciation of how acute inflammation and its natural resolution are regulated.

Systematic studies focusing on mechanisms of resolution and specialized chemical mediators gen- 
erated within resolution $(11,12)$ have uncovered n-3 PUFAs as endogenous precursors of resolvins and protectins. The small molecule members of these families have unique structures and independent routes of biosynthesis, yet share anti-inflammatory and proresolving properties in vivo. Their aspirintriggered epimeric forms of both families of compounds, namely the aspirin-triggered resolvins and protectin family epimers, are endogenously generated with aspirin treatment in murine models in vivo $(12,13)$. These aspirin forms share the characteristic features dampening inflammation and PMNmediated injury from within, key culprits in many widespread human diseases. These findings suggest that aspirin is unique among anti-inflammatory drugs because it jump-starts resolution by generating epimers of resolution mediators. In addition, the studies summarized here underscore the role(s) of PUFA-derived local mediators in resolution and tissue catabasis or the return to homeostasis $(20,32)$. These actions provide evidence for endogenous anti-inflammatory and proresolving mechanism(s) that may account in part for some of the beneficial actions of dietary n-3 PUFAs. Given their potent bioactivity and specific actions within resolution, the lipoxins (35), resolvins and protectins (Tables 1 and 2) and their mimetics now qualify as agonists for resolution in this new arena of resolution-modulation and tissue protection.

\section{Acknowledgements}

Studies in the author's laboratory were supported in part by National Institutes of Health grants GM38675, DK074448 and P-50 DE-016191. The author also thanks Stacey Lindberg and Mary Halm Small for assistance in preparing this manuscript.

\section{References}

1. Burr GO, Burr MM. A new deficiency disease produced by the rigid exclusion of fat from the diet. J Biol Chem 1929; 82: 345-67.

2. Lands WEM, ed. Proceedings of the AOCS Short Course on Polyunsaturated Fatty Acids and Eicosanoids. Champaign, IL: American Oil Chemists' Society; 1987.

3. Bazan NG. Supply of n-3 polyunsaturated fatty acids and their significance in the central nervous system. In: Wurtman RJ, Wurtman JJ, eds. Nutrition and the brain. New York: Raven Press; 1990. p. 1-22.

4. Simopoulos AP, Leaf A, Salem N Jr. Workshop on the essentiality of and recommended dietary intakes for omega-6 and omega-3 fatty acids. J Am Coll Nutr 1999; 18: 487-9.

5. Salem N Jr, Litman B, Kim H-Y, Gawrisch K. Mechanisms of action of docosahexaenoic acid in the nervous system. Lipids 2001; 36: 945-59.

6. Hansson G, Robertson AKL, Soderberg-Naucler C. Inflammation and atherosclerosis. Annu Rev Pathol Mech Dis 2006; 1: 297-329.

7. Erlinger TP, Platz EA, Rifai N, Helzlsouer KJ. $\mathrm{C}$-reactive protein and the risk of incident colorectal cancer. JAMA 2004; 291: 585-90.

8. Nathan C. Points of control in inflammation. Nature 2002; 420: 846-52.

9. Van Dyke TE, Serhan CN. Resolution of inflammation: a new paradigm for the pathogenesis of periodontal diseases. J Dent Res 2003; 82: 82-90.

10. Lukiw WJ, Cui JG, Marcheselli VL, Bodker M, Botkjaer A, Gotlinger K, et al. A role for docosahexaenoic acid-derived neuroprotectin D1 in neural cell survival and Alzheimer disease. J Clin Invest 2005; 115: 2774-83.

11. Serhan CN, Clish CB, Brannon J, Colgan SP, Chiang N, Gronert K. Novel functional sets of lipid-derived mediators with antiinflammatory actions generated from omega-3 fatty acids via cyclooxygenase 2-nonsteroidal antiinflammatory drugs and transcellular processing. J Exp Med 2000; 192: 1197-204.

12. Serhan CN, Hong S, Gronert K, Colgan SP, Devchand PR, Mirick G, et al. Resolvins: a family of bioactive products of omega-3 fatty acid transformation circuits initiated by aspirin treatment that counter pro-inflammation signals. J Exp Med 2002; 196: 1025-37.

13. Hong S, Gronert K, Devchand P, Moussignac R-L, Serhan CN. Novel docosatrienes and 17S-resolvins generated from docosahexaenoic acid in murine brain, human blood and glial cells: autacoids in anti-inflammation. J Biol Chem 2003; 278: 14677-87.

14. Marcheselli VL, Hong S, Lukiw WJ, Hua Tian X, Gronert K, Musto A, et al. Novel docosanoids inhibit brain ischemia-reperfusion-mediated leukocyte infiltration and pro-inflammatory gene expression. J Biol Chem 2003; 278: 43807-17.

15. Mukherjee PK, Marcheselli VL, Serhan CN, Bazan NG. Neuroprotectin D1: a docosahexaenoic acid-derived docosatriene protects human retinal pigment epithelial cells from oxidative stress. Proc Natl Acad Sci U S A 2004; 101: 8491-6.

16. Serhan CN, Gotlinger K, Hong S, Lu Y, Siegelman J, Baer $\mathrm{T}$, et al. Anti-inflammatory actions of neuroprotectin D1/protectin D1 and its natural stereoisomers: assignments of dihydroxy-containing docosatrienes. J Immunol 2006; 176: 1848-59.

17. Corey EJ, Shih C, Cashman JR. Docosahexaenoic acid is a strong inhibitor of prostaglandin but not leukotriene biosynthesis. Proc Natl Acad Sci U S A 1983; 80: $3581-4$.

18. Lee TH, Mencia-Huerta J-M, Shih C, Corey EJ, Lewis RA, Austen KF. Effects of exogenous arachidonic, eicosapentaenoic, and docosahexaenoic acids on the generation of 5-lipoxygenase pathway products by 
ionophore-activated human neutrophils. J Clin Invest 1984; 74: 1922-33.

19. Arita M, Bianchini F, Aliberti J, Sher A, Chiang N, Hong S, et al. Stereochemical assignment, anti-inflammatory properties, and receptor for the omega-3 lipid mediator resolvin E1. J Exp Med 2005; 201: 713-22.

20. Bannenberg GL, Chiang N, Ariel A, Arita M, Tjonahen $\mathrm{E}$, Gotlinger $\mathrm{KH}$, et al. Molecular circuits of resolution: formation and actions of resolvins and protectins. J Immunol 2005; 174: 4345-55.

21. Arita M, Yoshida M, Hong S, Tjonahen E, Glickman JN, Petasis NA, et al. Resolvin E1, a novel endogenous lipid mediator derived from omega-3 eicosapentaenoic acid, protects against TNBS-induced colitis. Proc Natl Acad Sci U S A 2005; 102: 7671-6.

22. Hasturk H, Kantarci A, Ohira T, Arita M, Ebrahimi N, Chiang N, et al. RvE1 protects from local inflammation and osteoclast mediated bone destruction in periodontitis. FASEB J 2006; 20: 401-3.

23. Duffield JS, Hong S, Vaidya V, Lu Y, Fredman G, Serhan CN, Bonventre JV. Resolvin D series and protectin D1 mitigate acute kidney injury. J Immunol 2006; 177: 5902-11.

24. Ariel A, Li P-L, Wang W, Tang W-X, Fredman G, Hong $\mathrm{S}$, et al. The docosatriene protectin D1 is produced by $\mathrm{T}_{\mathrm{H}} 2$ skewing and promotes human $\mathrm{T}$ cell apoptosis via lipid raft clustering. J Biol Chem 2005; 280: 43079-86.

25. Gronert K, Maheshwari N, Khan N, Hassan IR, Dunn M, Schwartzman ML. A role for the mouse 12/15lipoxygenase pathway in promoting epithelial wound healing and host defense. J Biol Chem 2005; 280: $15267-78$.

26. González-Périz A, Planagumà A, Gronert K, Miquel R, López-Parra M, Titos E, et al. Docosahexanenoic acid (DHA) ameliorates necroinflammatory liver injury by conversion to protective lipid mediators: protectin D1 and 17-hydroxy-DHA. FASEB J 2006;(in press) DOI: 10.1096/fj06-6250fje (http://www.fasebj.org).

27. Samuelsson B. From studies of biochemical mechanisms to novel biological mediators: prostaglandin endoperoxides, thromboxanes and leukotrienes. In: Les Prix Nobel: Nobel Prizes, presentations, biographies and lectures. Stockholm: Almqvist \& Wiksell; 1982. p. $153-74$.

28. Samuelsson B. Leukotrienes: mediators of immediate hypersensitivity reactions and inflammation. Science 1983; 220: 568-75.

29. Vane JR. Adventures and excursions in bioassay: the stepping stones to prostacyclin. In: Les Prix Nobel: Nobel Prizes, presentations, biographies and lectures. Stockholm: Almqvist \& Wiksell; 1982. p. 181-206.

30. Bergström S. The prostaglandins: from the laboratory to the clinic. In: Les Prix Nobel: Nobel Prizes, presentations, biographies and lectures. Stockholm: Almqvist \& Wiksell; 1982. p. 129-48.

31. Cotran RS, Kumar V, Collins T, eds. Robbins pathologic basis of disease. 6th edn. Philadelphia, PA: WB Saunders; 1999.
32. Serhan CN, Savill J. Resolution of inflammation: the beginning programs the end. Nature Immunol 2005; 6 : 1191-7.

33. Lawrence T, Willoughby DA, Gilroy DW. Anti-inflammatory lipid mediators and insights into the resolution of inflammation. Nat Rev Immunol 2002; 2: 787-95.

34. Levy BD, Clish CB, Schmidt B, Gronert K, Serhan CN. Lipid mediator class switching during acute inflammation: signals in resolution. Nature Immunol 2001; 2: 612-9.

35. Serhan CN, ed. Special Issue on lipoxins and aspirintriggered lipoxins. Prostaglandins Leukot Essent Fatty Acids 2005;73(3-4).

36. Majno G, Joris I. Cells, tissues and disease: of general pathology. Cambridge, MA: Blackwell Science; 1996.

37. Serhan CN. Lipoxins and aspirin-triggered 15-epilipoxin biosynthesis: an update and role in anti-inflammation and pro-resolution. Prostaglandins Other Lipid Mediat 2002; 68-69: 433-55.

38. Gilroy DW, Lawrence T, Perretti M, Rossi AG. Inflammatory resolution: new opportunities for drug discovery. Nat Rev Drug Discov 2004; 3: 401-16.

39. GISSI-Prevenzione Investigators. Dietary supplementation with $n-3$ polyunsaturated fatty acids and vitamin $E$ after myocardial infarction: results of the GISSI-Prevenzione trial. Gruppo Italiano per lo Studio della Sopravvivenza nell'Infarto miocardico. Lancet 1999; 354: 447-55.

40. Marchioli R, Barzi F, Bomba E, Chieffo C, Di Gregorio D, Di Mascio R, et al. Early protection against sudden death by $n-3$ polyunsaturated fatty acids after myocardial infarction: time-course analysis of the results of the Gruppo Italiano per lo Studio della Sopravvivenza nell'Infarto Miocardico (GISSI)-Prevenzione. Circulation 2002; 105: 1897-903.

41. Bazan NG. Supply, uptake, and utilization of docosahexaenoic acid during photoreceptor cell differentiation. Nestle Nutrition Workshop Series 1992; 28: 121-33.

42. Hamberg M, Samuelsson B. On the specificity of the oxygenation of unsaturated fatty acids catalyzed by soybean lipoxidase. J Biol Chem 1967; 242: 5329-35.

43. Sawazaki S, Salem N Jr, Kim H-Y. Lipoxygenation of docosahexaenoic acid by the rat pineal body. J Neurochem 1994; 62: 2437-47.

44. Reich EE, Zackert WE, Brame CJ, Chen Y, Roberts LJ II, Hachey DL, et al. Formation of novel D-ring and Ering isoprostane-like compounds $\left(\mathrm{D}_{4} / \mathrm{E}_{4}\right.$-neuroprostanes) in vivo from docosahexaenoic acid. Biochemistry 2000; 39: 2376-83.

45. VanRollins M, Baker RC, Sprecher HW, Murphy RC. Oxidation of docosahexaenoic acid by rat liver microsomes. J Biol Chem 1984; 259: 5776-83.

46. Winyard PG, Willoughby DA, eds. Inflammation protocols. Totowa, NJ: Humana; 2003.

47. Lu Y, Hong S, Gotlinger K, Serhan CN. Lipid mediator informatics and proteomics in inflammation-resolution. ScientificWorldJournal 2006;6: 589-614.

48. Lu Y, Hong S, Tjonahen E, Serhan CN. Mediatorlipidomics: databases and search algorithms for PUFAderived mediators. J Lipid Res 2005; 46: 790-802. 
49. Rowley AF, Lloyd-Evans P, Barrow SE, Serhan CN. Lipoxin biosynthesis by trout macrophages involves the formation of epoxide intermediates. Biochemistry 1994; 33: 856-63.

50. Bazan NG, Birkle DL, Reddy TS. Docosahexaenoic acid (22:6, n-3) is metabolized to lipoxygenase reaction products in the retina. Biochem Biophys Res Commun 1984; 125: 741-7.

51. Arita M, Bianchini F, Aliberti J, Sher A, Yang R, Petasis NA, et al. Novel omega-3 autacoid resolvin E1: receptor identification and anti-inflammatory properties. J Leukoc Biol 2003;Suppl:31 (Abstract 72).

Professor Charles N. Serhan

Center for Experimental Therapeutics and Reperfusion Injury Brigham and Women's Hospital 75 Francis Street Thorn Building for Medical Research, Room 724 Boston, MA 021 I 5 USA

Tel: + | 6177328822

Fax: $+|617582614|$

E-mail: cnserhan@zeus.bwh.harvard.edu 